\title{
An effect analysis of changes in the composition of the water ecological footprint in Jiangyin City, China
}

\author{
Dan Hu ${ }^{1}$, Feng $L^{1}{ }^{1}$, Bennan Wang ${ }^{1}$, Kampeng Lei $i^{2}$, Aixin Cao ${ }^{2}$, Zhen Wang ${ }^{1}$ and Lin Yin-Hua ${ }^{3}$ \\ ${ }^{1}$ State Key Laboratory of Urban \& Regional Ecology, Research Center for Eco-environmental \\ Sciences, Chinese Academy of Sciences, Beijing, China \\ ${ }^{2}$ Faculty of Science and Technology, University of Macao, MSAR, China \\ ${ }^{3}$ Chinese Academy of Forestry Sciences, Beijing, China
}

Key words: Water ecological footprint, freshwater ecosystems, sensitivity test

\begin{abstract}
SUMMARY
Ecological footprint (EF) analysis is an effective tool to assess ecosystem appropriation, but weaknesses still exist. In order to estimate a city's ecosystem appropriation, we made two modifications to EF: 1) including different types of freshwater area in the calculating framework; and 2) re-adjusting all equivalent factors in terms of different types of freshwater. The modifications are mainly concerned with changes in the composition of freshwater areas in EF analysis; that is, the proportion of aquaculture freshwater and tap freshwater. An assumption of $25 \%$ of aquaculture freshwater was used to conduct a sensitivity test. It shows that variation of the proportion leads to different equivalent and yield factors for tap freshwater areas. The variations not only changes the EF of freshwater but also the total EF. The modified EF calculation served to assess ecosystem appropriation in Jiangyin city in 1998. By comparing the original and the modified EF, it was found that the ecological deficit was larger (2.19 ha per capita) in the modified calculation than in the original (2.16 ha per capita). The original calculation is an underestimate because direct consumption of freshwater was not fully included in its calculating framework. From the modified calculation, the EF for different categories of ecosystems decreased, from fossil energy land, arable land and pasture to built-up areas, which together occupy about $97.58 \%$ of the total EF. Fossil energy land occupied $68.55 \%$ of the total, while freshwater areas took only $0.62 \%$. The main ecological deficits were from fossil energy land, arable land, pasture and marine areas. Ecological supply is lacking within Jiangyin and relies on ecosystems outside the city to survive. Ecosystem management is indispensable to optimise the efficiency of ecosystem use and to expand the biological capacity of the city. The modified EF could provide a more reasonable instrument in policy-making and implementing sustainable management of ecosystems.
\end{abstract}

\section{INTRODUCTION}

Ecosystem appropriation has become an important topic in the last 10 years. Its involves two approaches: (1) estimating the appropriation of ecosystems on a physical scale of mass or energy

Correspondence: Feng Li, State Key Laboratory of Urban \& Regional Ecology, Research Center for Eco-environmental Sciences, Chinese Academy of Sciences, Beijing100085, China. E-mail: lifeng@rcees.ac.cn or hrcees@vip.sina.com 
flows (Vitousek et al. 1986; Postel et al. 1996), and (2) estimating the appropriation of ecosystems at spatial scales, such as the ecological footprint (EF) (Wackernagel and Rees 1996; Wackernagel et al. 1999a,b; Lasson et al. 1994; Hu 2000; Deutsch et al. 2000). The spatial-based approach indicates ecosystem appropriation using the bio-productive land area. This approach has two obvious advantages: (1) simplicity in calculation, and (2) high applicability in human-environmental interaction analysis. The method also has some obvious weaknesses and has received criticism (van den Bergh and Verbruggen 1999; van den Bergh et al. 1999; van Kooten and Bulte 2000; Rees 2000; Ayres 2000) and some modification (Jansson et al. 1999, Rees 2000; Simmons and Lewis 2000; Haberl et al. 2001; Lenzen et al. 2001; Hu 2002). The improvements focus on: (1) including more categories of ecosystems, such as freshwater areas and other ecosystems with very low bioproductivity, adding them to component-based or land disturbance-based real areas, or leaving them in individual categories of land but aggregating them by weights of bioproductivity (Folke et al. 1997; Deutsch et al. 2000; Simmons and Lewis 2000; Lenzen et al. 2001); (2) introducing other techniques of flux analysis for mass and energy, such as input-output analysis, into the calculation (Lenzen et al. 2001); (3) including more greenhouse gas emissions other than $\mathrm{CO}_{2}$ into EF analysis (Lenzen et al. 2001) ; and (4) injecting fisheries and biomass substitution into the calculation (Wackernagel et al. 2005).

In this paper, we have modified the calculation of the freshwater EF based on the original calculation framework proposed by Wackernagel and colleagues (Wackernagel and Rees 1996; Wackernagel et al. 1999a,b), making it more applicable for different conditions. The focus of our modification is to include two different types of freshwater areas (areas of aquaculture freshwater and tap freshwater) into the EF calculation. In addition, a case study using the modified method provides a comparison of the difference in results between the original and the modified calculation. Finally, a sensitivity test served to examine how changes in the composition of freshwater areas, expressed as the proportion of the two types of freshwater areas, influences the results of EF calculation.

\section{Ecosystem appropriation in Jiangyin in recent decades}

Jiangyin is on the south bank of the Yangtze River the largest river in China. The high proportion of water areas in its territory plays a crucial role in its development, and water ecosystem appropriation is one of the main factors affecting its natural pattern of ecosystems services (Figure 1). Jiangyin became an administrative municipality in 1987 and, since then, there has been enormous ecosystem appropriation caused by urban development. Scarcity in ecosystems services has become very severe, creating a special challenge for ecosystems management, where rapid urban development has caused an obvious reduction in the size of natural ecosystems in the last 30 years (Table 1). From 1990 to 1998, the area of urban areas increased by

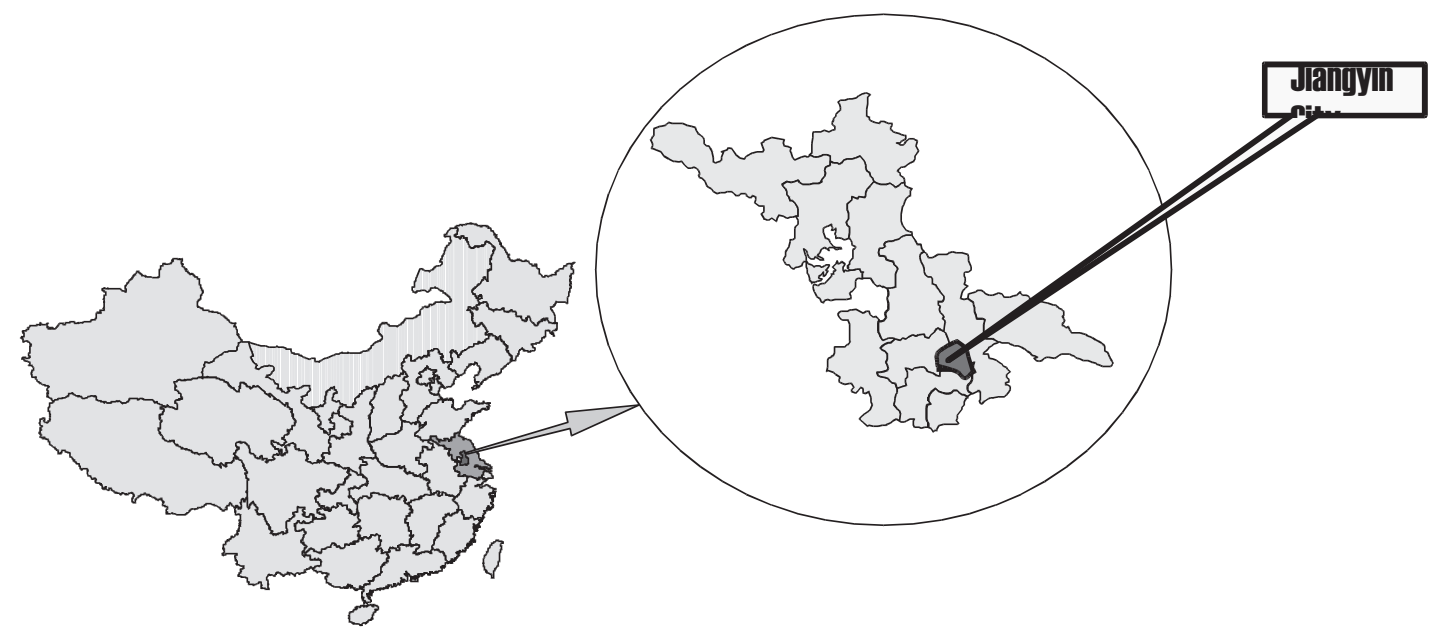

Figure 1 Location of Jiangyin city in China 
Table 1 Changes in the area of appropriated forest ecosystems driven by urban expansion in Jiangyin city from 1950 to 1998

\begin{tabular}{lcccc}
\hline Period & $1950-1960$ & $1970-1980$ & $1980-1990$ & $1990-1998$ \\
\hline Total urban area (ha) & - & 632.89 & 338.92 & 2248.06 \\
Forest area (ha) & $1386.44(+)$ & $555.12(-)$ & $1176.95(+)$ & $334.69(-)$ \\
Annual appropriation rate $\left(\mathrm{ha} \mathrm{y}^{-1}\right)$ & - & 63.3 & 33.9 & 224.8 \\
\hline
\end{tabular}

Note: + expresses an increase in forests, - refers to an decrease in forests. Data cited from Jiangyin Land Chorography 1998 and Jiangyin Statistical Yearbook 1998

1909.1 ha, with an annual appropriation rate of about 224.8 ha per year, much higher than that of the previous two decades. As the city has expanded, arable land per capita has decreased from 0.05 ha in 1980 to 0.04 ha in 1998 (Statistical Bureau of Jiangyin 1998). Many natural ecosystems have become built-up areas, and forest ecosystems have suffered a huge decline from 1980 to 1998.

The city covers 98300 ha, with a population of 1.14 million. Its GDP is 27.22 billion yuan (US\$1 = 8.0 yuan ), about 23810 yuan per capita in 1998 (Statistical Bureau of Jiangyin 1998), increasing from 624 yuan in 1980 to 7564 yuan in 1998 (at 1980 price level).

\section{METHODS}

\section{The original framework of EF calculation}

The first step in EF calculation for a given administrative area is to estimate the per capita area of appropriated ecosystems (aa) with the provision of $i$ th item of major products or services by dividing average annual consumption of $i$ th item ('c' in $\mathrm{kg}$ per capita) by its average annual productivity or yield ('p' in $\mathrm{kg} / \mathrm{ha}$ ):

$\mathrm{aa}_{\mathrm{i}}=\mathrm{c}_{\mathrm{i}} / \mathrm{p}_{\mathrm{i}}$

In practice, it is often only possible to estimate per capita consumption by dividing aggregate consumption by total population (N). Of course, many items of consumption (e.g. clothing and furniture) come from several inputs and it is useful to separately estimate the area appropriated by each significant input. The total per capita EF ('ef') can then be calculated by summing all areas of ecosystems appropriated by individual items in the annual shopping basket of goods and services:

$\mathrm{EF}=N\left[e f=\sum\left(a a_{i}\right)=\sum\left(c_{i} / p_{i}\right)\right]$
Thus, EF for a certain size of population is the per capita footprint multiplied by the population size $(\mathrm{N}): \mathrm{EF}=\mathrm{N}(\mathrm{ef})$.

It is useful to separate consumption into five major categories: food, housing, transportation, consumer goods and services. These categories can be subdivided as necessary. The 'embodied' energy and raw materials of a commodity is the total quantities of energy and materials used during the life cycle of that commodity, for its manufacture, transport and disposal. 'Energy intensity' refers to the direct embodied energy per unit of a good or service. Similarly, we can speak of the 'embodied EF' of a commodity as its contribution to the consumer EF.

\section{Modified EF calculation}

Modification of the original EF calculation is necessary to fully consider EF analysis of freshwater ecosystems. Our proposed modifications are outlined below.

\section{EF of freshwater in the calculation framework}

Inland waters add another 0.3 billion ha, giving 2.3 billion ha of potential fisheries out of the 36.6 billion ha of ocean and inland waters on our planet (FAO 1999). The majority of marine fish catches occur on continental shelves, and excluding inaccessible or unproductive waters leaves 2.0 billion ha. Although a fraction of the ocean's 36.3 billion ha, these 2.0 billion ha provide over $95 \%$ of marine fish catches (WRI 2000). The fishing footprint assumes additional by-catch according to the species composition of national or local fish catches. Inland water and continental shelf areas have replaced the EEZ (Exclusive Economic Zone) to give a far more accurate distribution of global fishing capacity (Wackernagel et al. 2005). 
Freshwater areas are important for human survival. They include inland areas such as rivers, lakes, reservoirs and other types of catchment, and differ from other types of ecosystem such as forest, grassland and arable land. As shortage of freshwater is a worldwide problem, freshwater ecosystem appropriation should not be omitted in any EF analysis. Therefore, two types of freshwater are considered in our modification: 1) areas for aquaculture fishery, and 2) areas for water supply to households, industries and capture fishery (abbreviated as tapwater). Agricultural water uses are not included here to avoid double counting, since they are possibly already included in cropland, grassland, forest and so on. The two kinds of freshwater area obviously differ from each other in bioproductivity, and they perform many ecological services for human welfare.

Similar to the original EF calculation, the supply and demand of freshwater ecosystems in terms of spatial area may be obtained according to their equivalent and yield factors. In our calculation, each EF (or the demand for aquaculture and tapwater) is calculated by converting the consumption quantity into freshwater ecosystem area as a global unit, and then summing the numbers (see Appendix I). This separate calculation leads to a higher global equivalent amount of freshwater EF, but a lower equivalent amount of freshwater supply in comparison with estimates from the compound calculation using average values of equivalent and yield factors for freshwater.

\section{Proportion of the two types of freshwater areas}

In conducting analysis of water EF, some scholars have included aquaculture freshwater areas; our modifications include both aquaculture and tapwater areas. Additionally, the area of freshwater for aquaculture is assumed to be approximately $25 \%$ of the total area of inland freshwater on a global scale; therefore, tapwater area should occupy the other $75 \%$. This hypothesis is applied to calculate global bioproductivities for aquaculture and tapwater.

\section{Fundamental ecological water uses and re-uses of wastewater}

The fundamental ecological water uses of freshwater are the minimum amount of water used to sustain the stability and resilience of local freshwater ecosystems (including their biodiversity). Wackernagel et al. (2005) suggested that $12 \%$ of the global surface is required for the other 30 million species on Earth, but he did not clearly specify the requirements for freshwater ecosystems maintenance and is possibly an underestimate of real water demand in freshwater ecosystems. Therefore, the concept of fundamental ecological water uses is introduced to estimate the actual amount required for freshwater ecosystem maintenance including hydro-biodiversity conservation. Our EF calculation assumed that $25 \%$ of the available freshwater (not the area of freshwater) is conserved for fundamental ecological water uses. The actual area needed for freshwater ecosystem maintenance can be determined from basic data on local hydrological balance and is approximately $12 \%$ of the local freshwater area. In our calculation, the amount of local fundamental ecological water uses is deducted from the total available local water stock. In addition, the reuse ratio of wastewater was determined to be $40 \%$ for living and industrial uses, according to statistical data for Jiangyin city.

\section{Adjustments to the parameters of equivalence factors for global bioproductive land}

According to Wackernagel and colleagues (2005), equivalence factors represent the world average potential productivity of a given bioproductive area relative to the world average potential productivity of all bioproductive areas. For example, the equivalence factor for crops describes potential biomass output attainable in an area with an assumed level of inputs, such as water and fertiliser. Cropland is more productive than rangeland or pasture, so it has a larger value for the equivalence factor than pasture. The equivalence factors for cropland, forest, pasture and built-up area in Wackernagel's calculation are derived from the suitability index of the Global Agro-Ecological Zones (GAEZ) in 2000, a spatial model of potential agricultural yields (Wackernagel et al. 2005). In this calculation, EF of fisheries was obtained from their capacity to supply animal protein relative to that of grassland.

In terms of the inclusion of two freshwater areas, we readjusted the equivalence factors according to differences in bioproductivity between freshwater and other categories of bioproductive areas. In our calculation, different types of ecosystems were 
Table 2 Parameters of equivalence factors for original and modified calculations

\begin{tabular}{lcc}
\hline Type of ecosystem & Equivalence factor (original) & Equivalence factor $($ modified) \\
\hline Fossil energy & 1.49 & 1.53 \\
Arable land for crops & 2.06 & 2.11 \\
Arable land for pasture & 0.62 & 0.64 \\
Pasture & 0.30 & 0.31 \\
Forest & 1.49 & 1.53 \\
Built-up areas & 2.06 & 2.11 \\
Aquaculture & No & 0.24 \\
Tap water & No & 0.40 \\
Marine areas & 1.22 & 1.26 \\
\hline
\end{tabular}

Note: Calculation of formulae and explanations for adjustments of equivalence factors are given in Appendix I

calculated according to FAO $(1999,2000)$ and WRI (2000, 2001) original data for agriculture, fisheries and freshwaters. The values of equivalence factors from our modified calculation is very similar to that of Wackernagel, except for marine areas, and differences mainly come from differences in data sources (Table 2). The productivity of global average bioproductive land is lower when freshwater ecosystem appropriation is introduced into the calculating framework (Table 2), since the productivity of freshwater is lower than that of arable land, forest or marine areas. In addition, the equivalence factors for various types of ecosystems are a little higher than that calculated without considering the two types of freshwater areas.

\section{RESULTS AND DISCUSSION}

For rapid development of Jiangyin relies on raw materials and energy that come directly or indirectly from natural ecosystems that release waste substances into the surroundings, causing negative effects or even damage to ecosystem service flows. However, the city often lacks necessary economic mechanisms to sustain its ecological service flows, leading to rapid uncontrolled shifts in natural ecosystems to built-up areas that become larger, while natural areas become smaller. Based on statistical data for Jiangyin (Statistical Bureau of Jiangyi, 1998; Jiangyin Land Chorography Compiling Committee 1998), annual ecosystem appropriation for 1998 was estimated by employing modified calculations (available from the authors). The main characteristics of EF in the city are:
1. Main products: including products consumed by city residents, such as beef, poultry, eggs, milk, fruit, aquatic products, sugar, cake, edible oil, fat, silk, tea, tobacco, alcoholic drinks, rubber products and timber. Indigenous natural ecosystems cannot provide enough products and raw materials, so some products are imported.

2. Freshwater: there is 47.34 million $\mathrm{m}^{3}$ of surface freshwater annually available for the city; the supply of freshwater mainly relies on inflows from the Yangtze River. The annual water imported is 0.83 billion $\mathrm{m}^{3}$, and about 0.32 billion $\mathrm{m}^{3}$ of this freshwater serves households and industries.

3. Energy: total energy consumption was 81.26 $\mathrm{Pj}$ in 1998, mainly coal, liquid or gas fossil fuels and hydroelectricity, and was imported from outside the city. Energy consumption of fossil fuels was 70.09 Pj, 86.26\& of the total. The embodied energy was $1.93 \mathrm{Pj}$ in imported goods and $15.15 \mathrm{Pj}$ in exported goods, and $68.39 \mathrm{Pj}$ in total net import of various products (including energy).

\section{EF of the city from the original calculation}

The EF of Jiangyin was calculated from the original calculation (Wackernagel et al. 2002, 2005) and the results are shown in Table 3 . There was an ecological deficit of 2.16 ha per capita. Types of ecosystems with a deficit are fossil energy land, arable land, pasture, forest, aquaculture and marine areas. 


\section{EF of the city from the modified calculation}

There was a 2.19-ha ecological deficit per capita, larger than that in the original calculation, and the ecological deficit was in fossil energy land, arable land, pasture, forest, marine areas and aquaculture areas (Table 4). Fossil energy land had the greatest deficit, followed by arable land. The four main types of appropriated ecosystem decreased gradually from fossil energy land, arable land and pasture to built-up area, and occupied $97.58 \%$ of the total EF (Table 4). The fractions of appropriated ecosystem components were: fossil energy land $68.55 \%$, arable land $19.56 \%$, pasture $7.64 \%$, forest $0.90 \%$, built-up areas $1.82 \%$, marine areas $0.91 \%$ and freshwater areas $0.62 \%$ of the total footprint. The main supplies of ecosystems in the city were: arable land
$33.90 \%$, built-up areas (originally arable land) $38.01 \%$, and freshwater areas $19.91 \%$ (Table 4).

\section{Comparison of EF analysis between the modified and original calculation}

The introduction of freshwater, especially tapwater, into the EF calculation framework changed the equivalent factors and yield factors, and thus made the results of EF calculation different (Table $5)$. The demand and supply per capita increased correspondingly, and ecological deficit per capita for all types of ecosystem except built-up area also increased in comparison with the original calculation. Therefore, the modified calculation gave higher EF values for supply and ecological deficits.

Table 3 Ecological demand and supply in 1998 with the original calculation

\begin{tabular}{|c|c|c|c|c|c|c|}
\hline \multirow[b]{2}{*}{ Category } & \multicolumn{3}{|c|}{ Demand (Footprint) [ha/cap] } & \multicolumn{3}{|c|}{ Supply(Biocapacity) [ha/cap] } \\
\hline & Area & $\begin{array}{c}\text { Equivalence } \\
\text { factor }\end{array}$ & $\begin{array}{c}\text { Equivalence } \\
\text { total }\end{array}$ & Area & Yield factor & $\begin{array}{c}\text { Yield adjusted } \\
\text { equiv. area }\end{array}$ \\
\hline Fossil energy & $1.07 \mathrm{E}+00$ & 1.49 & $1.59 \mathrm{E}+00$ & $0.00 \mathrm{E}+00$ & 1.14 & $0.00 \mathrm{E}+00$ \\
\hline Built-up areas & $2.06 \mathrm{E}-02$ & 2.06 & 4.23E - 02 & $2.06 \mathrm{E}-02$ & 1.84 & $7.78 \mathrm{E}-02$ \\
\hline Arable land & $2.21 \mathrm{E}-01$ & 2.06 & $4.54 E-01$ & $1.83 \mathrm{E}-02$ & 1.84 & $6.94 \mathrm{E}-02$ \\
\hline Pasture & $2.87 \mathrm{E}-01$ & 0.62 & $1.77 \mathrm{E}-01$ & $2.73 \mathrm{E}-02$ & 0.81 & $1.38 \mathrm{E}-02$ \\
\hline Forest & $1.40 \mathrm{E}-02$ & 1.49 & $2.08 E-02$ & $1.76 \mathrm{E}-03$ & 1.14 & $2.97 \mathrm{E}-03$ \\
\hline Marine areas & $1.72 \mathrm{E}-02$ & 1.22 & $2.10 \mathrm{E}-02$ & $\begin{array}{l}0.00 \mathrm{E}+00 \\
\text { TOTAL }\end{array}$ & 1.00 & $\begin{array}{l}0.00 \mathrm{E}+00 \\
\mathbf{1 . 6 4 E}-01\end{array}$ \\
\hline TOTAL & $1.63 E+00$ & & 2.3048 & TOTAL available & & 0.1442 \\
\hline \multicolumn{6}{|c|}{ Total ecological deficit (minus $12 \%$ for biodiversity) } & 2.1606 \\
\hline
\end{tabular}

Table 4 Ecological demand and supply in Jiangyin in 1998 with the modified calculation

\begin{tabular}{|c|c|c|c|c|c|c|}
\hline \multirow[b]{2}{*}{ Category } & \multicolumn{3}{|c|}{ Demand (Footprint) [ha/cap] } & \multicolumn{3}{|c|}{ Supply ( Biocapacity) [ha/cap] } \\
\hline & Area & $\begin{array}{l}\text { Equivalence } \\
\quad \text { factor }\end{array}$ & $\begin{array}{c}\text { Equivalence } \\
\text { total }\end{array}$ & Yield factor & Region area & $\begin{array}{c}\text { Yield adjusted } \\
\text { equiv. area }\end{array}$ \\
\hline Fossil energy & $1.07 \mathrm{E}-01$ & 1.53 & $1.63 E+00$ & $0.00 \mathrm{E}+00$ & 1.14 & $0.00 \mathrm{E}+00$ \\
\hline Built-up areas & $2.06 \mathrm{E}-02$ & 2.11 & $4.34 E-02$ & $2.06 \mathrm{E}-02$ & 1.84 & $7.99 \mathrm{E}-02$ \\
\hline Arable land & $2.21 \mathrm{E}-01$ & 2.11 & $4.66 \mathrm{E}-01$ & $1.83 \mathrm{E}-02$ & 1.84 & $7.13 \mathrm{E}-02$ \\
\hline Pasture & $2.87 \mathrm{E}-01$ & 0.64 & $1.82 \mathrm{E}-01$ & $2.73 \mathrm{E}-02$ & 0.81 & $1.41 \mathrm{E}-02$ \\
\hline Forest & $1.40 \mathrm{E}-02$ & 1.53 & $2.14 \mathrm{E}-02$ & $1.76 \mathrm{E}-03$ & 1.14 & $3.05 \mathrm{E}-03$ \\
\hline Marine areas & $1.72 \mathrm{E}-02$ & 1.26 & $2.16 \mathrm{E}-02$ & $0.00 \mathrm{E}+00$ & 1.00 & $0.00 \mathrm{E}+00$ \\
\hline Aquaculture & $5.90 \mathrm{E}-02$ & 0.24 & $1.40 \mathrm{E}-02$ & $9.32 \mathrm{E}-03$ & 10.08 & $1.02 \mathrm{E}-02$ \\
\hline Tapwater & $1.82 \mathrm{E}-03$ & 0.40 & $7.31 E-04$ & $\begin{array}{l}4.25 \mathrm{E}-03 \\
\text { TOTAL }\end{array}$ & 8.45 & $\begin{array}{l}3.17 \mathrm{E}-02 \\
\mathbf{2 . 1 0 E}-01\end{array}$ \\
\hline $\begin{array}{l}\text { TOTAL } \\
\text { Total ecologica }\end{array}$ & eficit (minus & $\%$ for biodive & 2.3840 & TOTAL available & & $\begin{array}{l}0.1901 \\
2.1939\end{array}$ \\
\hline
\end{tabular}


Table 5 Deviations of EF between the modified and original calculations

\begin{tabular}{lccc}
\hline Ecosystem category & $\begin{array}{c}\text { Deviation in demand } \\
{[\text { ha/cap] }}\end{array}$ & $\begin{array}{c}\text { Deviation in supply } \\
{[\text { ha/cap] }}\end{array}$ & $\begin{array}{c}\text { Deviation in ecological deficit } \\
\text { [ha/cap] }\end{array}$ \\
\hline Fossil energy & $4.44 \mathrm{E}-02$ & $0.00 \mathrm{E}+00$ & $4.44 \mathrm{E}-02$ \\
Arable land & $1.27 \mathrm{E}-02$ & $1.94 \mathrm{E}-03$ & $1.07 \mathrm{E}-02$ \\
Pasture & $4.95 \mathrm{E}-03$ & $3.85 \mathrm{E}-04$ & $4.57 \mathrm{E}-03$ \\
Forest & $5.82 \mathrm{E}-04$ & $8.31 \mathrm{E}-05$ & $4.98 \mathrm{E}-04$ \\
Built-up area & $1.18 \mathrm{E}-03$ & $2.17 \mathrm{E}-03$ & $-9.93 \mathrm{E}-04$ \\
Aquaculture area & - & - & - \\
Tapwater area & - & - & - \\
Marine area & $5.88 \mathrm{E}-04$ & $0.00 \mathrm{E}+00$ & $5.88 \mathrm{E}-04$ \\
Total & $\mathbf{0 . 0 7 9 2}$ & $\mathbf{0 . 0 4 5 9}$ & $\mathbf{0 . 0 3 3 3}$ \\
\hline
\end{tabular}

Note: Column 4 is the result of the modified calculation minus the original calculation

\section{Sensitivity test for the assumption of $\mathbf{2 5 \%}$ included in the modification}

The modification to the original EF calculation was based on an important assumption: the area of aquaculture freshwater is about $25 \%$ of total inland freshwater. By examining variations in the proportion of aquaculture areas from 15 to $35 \%$, should affect the values of equivalence factors and yield factors; therefore, a sensitivity test was conducted to show how deviation in EF calculation occur. Variation in the equivalence factor for aquaculture areas drops from $66.67 \%$ (a deviation of $-10 \%$ ) to $-28.57 \%$ (a deviation of $+10 \%$ ), and that for tapwater areas declines from $-11.76 \%$ (a deviation of $-10 \%$ ) to $15.38 \%$ (a deviation of $+10 \%$ ). Additionally, variation in the yield factor for aquaculture areas drops from $-40.00 \%$ (a deviation of $-10 \%$ ) to $40.00 \%$ (a deviation of $+10 \%$ ), and variation in the yield factor for tapwater areas decreases from $13.33 \%$ (a deviation of $-10 \%$ ) to $-13.33 \%$ (a deviation of $+10 \%)$. This showed that the variation relative to the assumption of $25 \%$ has a greater effect on the equivalence and yield factors of aquaculture areas than on tapwater areas.

For EF and ecological deficits, variation of per capita EF drops from $-0.0036 \%$ (a deviation of $-10 \%$ ) to $0.0047 \%$ (a deviation of $+10 \%$ ), and variation in per capita supply remains invariant. The variation in per capita deficits drops from $-0.0039 \%$ (a deviation of $-10 \%$ ) to $0.0051 \%$ (a deviation of $+10 \%$ ). This showed that the variation relative to the assumption of $25 \%$ has a relatively greater effect on per capita EF or demand and ecological deficits than on per capita supply. However, this effect is quite subtle (less than $\pm 0.01 \%$ ).

\section{CONCLUSIONS}

This research proposed modifications to the EF calculation. The modifications mainly dealt with two types of freshwater area into the original calculation. Compared with the original calculation, the modified form produced more appropriation and more ecological deficits, which consequently reflects much more exactly the situation for ecosystem appropriation by the city's development, and so reduces the underestimate. Including two types of freshwater area into the original calculation had an effect on the results of EF calculation. Due to lower productivity of freshwater than some other types of ecosystem, such as arable and forest, the inclusion of two types of freshwater area decreases the productivity of global average bioproductive land; thus, for the other types of ecosystem, the equivalence factors are a little higher than those without considering freshwater.

The change in the proportion between areas of aquaculture and tapwater areas led to variations in equivalence and yield factors for freshwater areas, and had a greater influence on equivalence and yield factors for aquaculture areas than on tapwater areas. The variations relative to the assumption of $25 \%$ as the proportion of aquaculture freshwater would not only change the EF of freshwater areas but also the total EF of the city, although not the supply of freshwater to the city. However, the influences of the variations relative to the assumption of $25 \%$ are not great.

Jiangyin's development has exerted great pressure on local ecosystems and greater dependence on external resources in maintaining the city's development. To advance the capacity of ecosystes 
services, ecosystems management is indispensable for the city to optimise the spatial distribution of ecosystem uses and enhance their efficiency (van den Bergh et al. 1999, Hu 1998, 2002; Wackernagel et al. 1999a, 2002). The modified EF calculation offers a better tool to help understand the city's condition in terms of ecosystem appropriation and promotes the implementation of sustainable ecosystems management.

\section{ACKNOWLEDGEMENTS}

This research was supported by the National Natural Sciences Foundation of China (Grant No. 70573106), the National Basic Research Program of China (Grant No. 2005CB724206) and the Knowledge Innovation Project of the Chinese Academy of Sciences (KZCX2-YW-324, KZCX2-YW-422).

\section{REFERENCES}

Ayres RU. Commentary on the utility of the ecological footprint concept. Ecological Economics 2000;32: 347-9

Bergh van den, JCJM and Verbruggen H. An evaluation of the 'Ecological Footprint': Reply to Wackernagel and Ferguson. Ecological Economics 1999;31:319-21

Bergh van den, JCJM and Verbruggen H. Spatial sustainability, trade and indicators: An evaluation of the 'Ecological Footprint'. Ecological Economics 1999;29:61-72

Deutsch L, Jansson A, Troell M, Rönnbäck P, Folke C and Kautsky N. The 'ecological footprint': communicating human dependence on nature's work. Ecological Economics 2000;32:351-5

FAO. FAOSTAT. http://faostat.fao.org/; 1999

FAO. FAOSTAT. http://faostat.fao.org/; 2000

Folke C, Jansson A, Larsson A and Costanza R. Ecosystems appropriation by cities. Ambio 1997;26(3): 167-72

Haberl H, Erb K-H and Krausmann F. How to calculate and interpret ecological footprints for long periods: the case of Austria 1926-1995. Ecological Economics 2001;38:25-45

$\mathrm{Hu}$ D. A theoretical approach to eco-capitals. In: Deng $\mathrm{N}$ et al. (eds), Sustainable Development: Humans Care for the Future. Harbin, China: Heilongjiang Education Press; 1998:285 pp.

$\mathrm{Hu} \mathrm{D}$. The appropriation of ecosystem assets by urban development in Jiangyin city, Jiangsu Province with Wackernagel's method. Proceedings of ZhuhaiMacao International Conference on Urban Ecology; 2000:78 pp.

$\mathrm{Hu}$ D. Eco-capital and its services in urbanization. IHDP Update. Newsletter of the International Human Dimensions Programme on Global Environmental Change 2002;3:16 pp.

Jansson A, Folke C, Rockström J and Gordon L. Linking freshwater flows and ecosystem services appropriated by people: the case of the Baltic Sea drainage basin. Ecosystems 1999;2:351-66
Jiangyin Land Chorography Compiling Committee. Jiangyin land chorography. Nanjing: Jiangsu People Press; 1998

Kooten van, CG and Bulte EH. The ecological footprint: useful science or politics? EcologicalEconomics 2000;32:385-9

Lasson J, Folke C and Kautsky N. Ecological limitations and appropriation of ecosystem support by shrimp farming in Colombia. Environmental Management 1994;18(5):663-76

Lenzen M and Murray SA. A modified ecological footprint method and its application to Australia. Ecological Economics 2001;37:229-55

Postel SL, Daily GC and Ehrlich PR. Human appropriation of renewable freshwater. Science 1996;271: $785-8$

Rees WE. Eco-footprint analysis: merits and brickbats. Ecological Economics 2000;32(3):371-4

Simmons C and Lewis K. Two feet - two approaches: a component-based model of ecological footprint. Ecological Economics 2000;32(3):375-80

Statistical Bureau of Jiangyin. Jiangyin Statistical Yearbook of Jiangyin. Beijing: China Statistical Publishing House; 1998

Vitousek PM, Ehrlich PR, Ehrlich AH and Matson PA. Human appropriation of the products of photosynthesis. BioScience 36(6):368-73

Wackernagel M and Rees WE. OurEcologicalFootprintReducing Human Impact on the Earth. Gabriola Island PA: New Society Publishers; 1996

Wackernagel M, Lewan L and Borgström-Hansson C. Evaluating the use of natural capital with the ecological footprint applications in Sweden and subregions. Ambio 1999a;28:604-12

Wackernagel M, Onist L, Bello $\mathrm{P}$ et al. National natural capital accounting with the ecological footprint concept. Ecological Economics 1999b;29: 375-90

Wackernagel M, Schulz NB, Deumling D et al. Tracking the ecological overshoot of the human economy. PNAS 2002;99(14):9266-71 
Wackernagel M, Monfreda C, Moran D et al. National Footprint and Biocapacity Accounts 2005: The underlying calculation method. Global Footprint Network; 2005

WRI. World Resources 2000-2001-People and Ecosystems: The Fraying Web of Life. Washington DC: World Resources Institute; 2000
WRI. World Resources Report 2000-2001. Washington DC: World Resources Institute; 2001 


\section{Appendix I Explanations for the modified calculation used in EF analysis}

\section{Equivalence and yield factors for freshwater areas}

The calculation processes for equivalence and yield factors were performed according to Wackernagel (1999, 2002, 2005):

Bio-productivity of global average bioproductive areas $(\mathrm{kg} / \mathrm{ha} / \mathrm{yr})=$ total bioproduction of global average bioproductive areas $(\mathrm{kg} / \mathrm{yr}) /$ total area of global average bi-productive areas (ha/yr).

Based on the above expression, equivalence and yield factors for inland freshwater areas are:

1) Equivalence factor for freshwater areas = bioproductivity of global freshwater areas $(\mathrm{kg} / \mathrm{ha} / \mathrm{yr}) /$ bioproductivity of global average bioproductive areas $(\mathrm{kg} / \mathrm{ha} / \mathrm{yr})$;

2) Equivalence factor for tapwater areas = bioproductivity of global tapwater areas $(\mathrm{kg} / \mathrm{ha} / \mathrm{yr}) /$ bioproductivity of global average bioproductive areas $(\mathrm{kg} / \mathrm{ha} / \mathrm{yr})$;

3) Equivalence factor for aquaculture freshwater areas = bioproductivity of global aquaculture freshwater areas $(\mathrm{kg} / \mathrm{ha} / \mathrm{yr}) /$ bi-productivity of global average bioproductive areas $(\mathrm{kg} / \mathrm{ha} / \mathrm{yr})$;

4) Yield factor for local aquaculture freshwater areas = bioyield of local aquaculture freshwater areas $(\mathrm{kg} / \mathrm{ha} / \mathrm{yr}) /$ bioyield of global aquaculture freshwater areas $(\mathrm{kg} / \mathrm{ha} / \mathrm{yr})$;

5) Yield factor of local tapwater areas = yield of local tapwater areas $(\mathrm{kg} / \mathrm{ha} / \mathrm{yr}) /$ bioyield of global tapwater areas $(\mathrm{kg} / \mathrm{ha} / \mathrm{yr})$;

6) Average water output for global tapwater areas $(\mathrm{kg} / \mathrm{ha} / \mathrm{yr})=$ total water amount available to global tapwater areas $(\mathrm{kg} / \mathrm{yr}) /$ total area of global tapwater areas $(\mathrm{ha} / \mathrm{yr})$, this value contains fundamental ecological water uses of tapwater areas.

\section{Sensitivity test for main parameters and variables of EF calculation}

The sensitivity test examines how key parameters and variables of EF calculation, such as equivalence factors, yield factors, demand, supply and deficits change when the assumed value for the area of freshwater for aquaculture is about $25 \%$ of the total area of inland freshwater at a global scale vary $\pm 10 \%$.

1) Variations of equivalence or yield factors relative to the assumed $25 \%$

$=$ [equivalence or yield factor of any type of freshwater area at the assumed value of any percentage equivalence or yield factor at the assumed value of $25 \%$ ] / equivalence or yield factor at the assumed value of $25 \% * 100 \%$.

2) Variations of per capita demand, supply and ecological deficits relative to the assumption of $25 \%$

$=$ [per capita demand, supply and ecological deficits at the assumed value of any percentage - per capita demand, supply and ecological deficits at the assumed value of $25 \%$ ] / per capita demand, supply and ecological deficits at the assumed value of $25 \% * 100 \%$.

\section{EF and supply calculation for freshwater areas in equivalent units}

1) Per capita EF of aquaculture freshwater areas

$=$ total local consumption of aquatic products $(\mathrm{kg} / \mathrm{yr}) /$ bioyield of global aquaculture freshwater areas $(\mathrm{kg} / \mathrm{ha} / \mathrm{yr}) *$ equivalence factor for aquaculture freshwater areas/total local population;

2) Per capita EF of tapwater areas 
$=$ total local freshwater consumption $(\mathrm{kg} / \mathrm{yr})$ average water output for global tapwater areas $(\mathrm{kg} / \mathrm{ha} / \mathrm{yr})$ * equivalence factor for tapwater areas/total local population;

3) Total per capita EF of freshwater areas

= per capita $\mathrm{EF}$ of aquaculture freshwater areas + per capita $\mathrm{EF}$ of tapwater areas;

4) Per capita supply of tapwater areas

$=$ total local tapwater areas $(\mathrm{ha} / \mathrm{yr}) *$ equivalence factor for tapwater areas * yield factor for local tapwater areas/total local population.

\section{Calculation of conserved rate of fundamental ecological water uses of freshwater areas}

As Wackernagel suggested (1999, 2002, 2005), 12\% of bioproductive areas is conserved for biodiversity maintenance in EF calculations, but this is not completely applicable in our case study. In our calculation, when the percentage of freshwater areas actually needed for fundamental ecological water uses (hydrobiodiversity maintenance requirement already included) is less than $12 \%$, this assumption is applicable; but when this value is more than $12 \%$, the assumption is not applicable and the percentage actually needed for local fundamental ecological water uses is adopted. 